DOI: $10.20472 /$ IAC.2017.031.013

\author{
ANIRBAN CHAKRABORTY \\ Indian Institute of Management Lucknow, India
}

AMIT TIWARI

Indian Institute of Management Lucknow, India

\title{
EFFECT OF CONVERGENT PRODUCT PERCEPTION ON EXPERIENTIAL BRAND LOYALTY: AN INTERACTIVE DEVICE VIEWPOINT
}

\begin{abstract}
:
The profusion of convergent products is a reigning paradigm \& key characteristic of contemporary products. The boundaries between products are disappearing rapidly due to convergence.

In this study, we propose a conceptual model and theorise about the impact of convergent product dimensions on brand loyalty mediated through user experience. In the effort to understand convergent product perception more carefully, this study proposes six attributes of convergent product: Usefulness, Ease of use, Aesthetics, Innovativeness of technology, Self-expression, Entertainment. It is the user experience, arising as a consequence of convergent product usage that can lead to brand loyalty. The proposed model thus sees user experience as an mediating factor when it comes to the relationship between convergent product perception and brand loyalty. It is pertinent that each element of the convergent product should enhance the experience of the consumer while using the product on a day to day basis.
\end{abstract}

This study integrates three branches of literature viz. convergent product literature, brand loyalty, and user experience literature; This makes the work a novel attempt to integrate concepts of convergent product dimensions, user experience, and brand loyalty.

Regarding contribution, this study should provide an indication to the designers and marketers, what Convergent product dimensions are considered most important by the user as well as their contribution to the market success of a convergent product. The model can also be used as a tool to ensured success of a particular convergent product which provides different levels of the dimension of convergent product.

\section{Keywords:}

Convergent product, Brand loyalty, User Experience, Entertainment

JEL Classification: M31 